\title{
Price and non-price restraints when retailers are vertically differentiated
}

\author{
by \\ Yossi Spiegel and Yaron Yehezkel* \\ Berglas School of Economics, Tel Aviv University \\ January 31, 2000
}

\begin{abstract}
This paper considers vertical restraints in the context of an intrabrand competition model in which a single manufacturer deals with two vertically differentiated retailers. We establish two main results. First, if the market cannot be vertically segmented, the manufacturer will foreclose the low quality retailer either directly by dealing exclusively with the high quality retailer, or indirectly by setting a sufficiently high minimum resale price maintenance or a sufficiently high wholesale price to ensure that the low quality retailer cannot make a positive profit. Second, if the market can be vertically segmented, the manufacturer will impose customer restrictions by requiring the low quality retailer to deal only with consumers whose willingness to pay for quality is below some threshold. We show that this restriction benefits the manufacturer as well as consumers with low willingness to pay for quality, including some that are served by the high quality retailer, but it harms consumers with high willingness to pay for quality.
\end{abstract}

Keywords: vertical restraints, exclusive dealings, vertical foreclosure, retail price maintenance, customer restrictions

JEL Classification Numbers: L42, K21

* Berglas School of Economics, Tel Aviv University, Ramat Aviv, Tel Aviv, 69978, Israel. Emails: <y-spiegel@nwu.edu> and <yehezkel@post.tau.ac.il>. 


\section{Introduction}

Vertical restraints in the relationship between manufacturers and distributors or retailers, such as resale price maintenance (RPM), exclusive territories, and customer restriction are the subject of an ongoing legal and academic debate. On one side of the debate, advocates of the Chicago school argue that the main purpose of vertical restraints is improve the efficiency of vertical relationships and hence should pose no antitrust concerns. For example, Esterbrook (1984) claims that: "No practice a manufacturer uses to distributes its products should be a subject to serious antitrust attention. It should make no difference whether the manufacturer prescribes territories, customers, quality standards, or prices for its dealers... They are all the same." On the other side of the debate, those like Pitofsky $(1978,1983)$ and Comanor and Frech (1985) discount the welfare enhancing properties of vertical restraints and emphasizes their potential anticompetitive effects. Traditionally, the courts in the U.S. have treated price restraints as per se illegal, while the treatment of non-price based restriction has varied sharply over the years, thereby reflecting the lack of consensus regarding the competitive effects of these practices. ${ }^{1}$

In this paper we consider the impact of vertical restraints in the context of an intrabrand competition model in which a single manufacturer deals with two vertically differentiated retailers. The two retailers differ from one another with respect to the quality of the services that they provide in addition to the manufacturer's product. These services could either be presale services such as highly trained sales staff, technical advice, demonstrations (e.g., fitting rooms or listening rooms for stereo), ambient atmosphere, quick delivery, and convenient financing plans, or postsale services such as extended in store warranties, generous return policies, and

1 The per se illegality of price restraints was first established by the U.S. Supreme court in 1911 in the Dr. Miles Medical Co. v. John D. Park Sons Co. 220 U.S. 373 (1911). In recent years the Court has progressively narrowed the scope of the per se illegality rule in the Monsanto Co. v. Spray-Rite Service Corp. 465 U.S. 752, 761 (1984) and in the Business Electronics Corp. v. Sharp Electronic Corp. 485 U.S. 717, 724 (1988) cases. With regard to non-price restraints, the Court has ruled in 1967 in the US v. Arnold Schwinn \& Co. 388 U.S. 365 that territorial restrictions were also illegal per se. In 1977 however, the Court has reversed this decision in the Continental T.V. Inc. v. GTE Sylvania 433 U.S. 36 case. For excellent surveys of the law and economics of vertical restraints, see Mathewson and Winter $(1985,1998)$, and Comanor and Rey (1997). 
reliable maintenance and repair services. We establish two main results. The first result concerns markets in which consumers cannot be vertically segmented according to their willingness to pay for quality. We show that in these markets the manufacturer will foreclose the low quality retailer and deal exclusively with the high quality retailer regardless of whether vertical restraints can or cannot be used. Although foreclosure means that only the high end of the market is served, the absence of competition from a low quality retailer enables the high quality retailer to earn higher profits, which in turns allows the manufacturer to charge a higher franchise fee.

The result that foreclosure occurs even if the manufacturer cannot use vertical restraints has an important implication for evaluating the desirability of restraints. One argument that is frequently made to support the use of vertical restraints is that they can alleviate a free-rider problem in the provision of special services by retailers (Telser 1960). This argument suggests that if the quality of the retailers' services is subject to a moral hazard problem, then dealing exclusively with the high quality retailer may boost the quality of service and thereby enhance welfare. Likewise, following Marvel and McCafferty (1984), it could be argued that if consumers are imperfectly informed about the quality of the manufacturer's product, then the decision to deal exclusively with a high quality retailer may signal high quality to consumers and therefore be desirable. However, since we establish that foreclosure occurs even without vertical restraints, it is clear that the benefits associated with foreclosure cannot be used to justify the use of vertical restraints. In fact we show that the use of vertical restraints benefits the manufacturer and harms consumers and social welfare because it leads to higher retail prices.

The second main result of the paper concerns markets that can be vertically segmented. We show that in these markets, the manufacturer will impose customer restrictions by requiring the low quality retailer to deal only with consumers whose willingness to pay for quality is below some threshold. This restriction shields the high quality retailer from competition from the low quality retailer and hence allows the manufacturer to charge a higher franchise fee from the high quality retailer without loosing the ability to serve the low end of the market. Although the restriction eliminates competition between the two retailers it nonetheless benefits consumers with relatively low willingness to pay for quality, including some which are served by the high quality retailer, although it harms consumers at the top end of the market. 
Most of the literature on vertical restraints has focused on the case where retailers are horizontally differentiated (see for example the literature surveys in Mathewson and Winter, 1985; Ch. 4 in Tirole, 1988; and Katz, 1989). Notable exceptions are Bolton and Bonnano (1988) and Winter (1993). Bolton and Bonnano (1988) consider a model with one manufacturer and two retailers who can choose the quality of their services. They show that although RPM and franchise fees allow the manufacturer to earn more money then he would earn with a uniform wholesale price, they do not restore the profits under vertical differentiation. Winter (1993) considers the role of vertical restraints in a model with both vertical and horizontal differentiation. In his model, a manufacturer deals with two retailers that are located at the opposite ends of a line segment and can choose the quality of their services which is associated in the Winter model with the speed with which consumers can purchase the product. Winter shows that RPM and Exclusive Territories implement the first-best solution. In both papers however the retailers can choose their quality of service so there is no foreclosure in equilibrium. Moreover the two papers do not consider customer restrictions.

The rest of the paper is organized as follows: in Section 2 we describe the model. Then in Section 3 we solve for the optimal two-part tariff set by the manufacturer in the absence of any vertical restraints. Then in Section 4 we consider markets that cannot be segmented vertically according to the willingness of consumers to pay for quality and we solve for the equilibrium when the manufacturer can refuse to deal with one of the retailers or use an RPM. In section 5 we consider markets in which customers can be sorted according to their marginal willingness to pay for quality and we solve for the optimal vertical segmentation of the market. In section 6 we offer concluding remarks. 


\section{The model}

Consider a manufacturer who produces a single product. The manufacturer does not have the capability to sell the product directly to consumers and needs to rely on downstream retailers. There are two downstream retailers, one that provides a high quality service and is referred to as retailer $\mathrm{H}$ and another that provides a low quality service and is referred to as retailer $\mathrm{L}$. The services that the retailers provide are either presale services such as highly trained sales staff, technical advice, demonstrations (e.g., fitting rooms or listening rooms for stereo), ambient atmosphere, quick delivery, and convenient financing plans, or postsale services such as extended in store warranties, generous return policies, and reliable maintenance and repair services.

We assume that there is a continuum of potential consumers with a total mass of 1 , each of whom buys at most one unit of the product. The consumers differ from one another with respect to their marginal valuations of quality. Given the retail prices $\mathrm{p}_{\mathrm{H}}$ and $\mathrm{p}_{\mathrm{L}}$ set by retailers $\mathrm{H}$ and $\mathrm{L}$, the utility of a consumer whose marginal valuation of quality is $\theta$ is given by

$$
U(\theta)=\left\{\begin{array}{cl}
S \theta-p_{H}, & \text { if the consumer buys from retailer } H, \\
\gamma S \theta-p_{L}, & \text { if the consumer buys from retailer } L, \\
0, & \text { if the consumer does not buy at all, }
\end{array}\right.
$$

where $0<\gamma<1$. The parameter $\gamma$ measures of the degree to which the services of the two retailers are differentiated with lower values of $\gamma$ being associated with a greater degree of vertical differentiation.

In what follows, we shall refer to $\theta$ as the consumer's type. We assume that consumers' types are drawn from a smooth distribution function $\mathrm{f}(\theta)$ on the interval $[0, \bar{\theta}]$, with a cumulative distribution function $\mathrm{F}(\theta)$. In addition, we also assume that the inverse of the hazard rate of the distribution of types, $\mathrm{H}(\theta) \equiv(1-\mathrm{F}(\theta)) / \mathrm{f}(\theta)$ is nonincreasing; this assumption is satisfied by standard continuous distributions (e.g., uniform, exponential, and normal), and it ensures that the second order conditions for the different maximization problems that we consider below are satisfied.

Apart from their different qualities of service, the two retailers also differ from one another in the cost of their services: the per unit cost of retailer $\mathrm{H}$ is $\mathrm{c}_{\mathrm{H}}$ while the per unit cost 
of retailer $\mathrm{L}$ is $\mathrm{c}_{\mathrm{L}}$, where $\mathrm{c}_{\mathrm{L}}<\mathrm{c}_{\mathrm{H}}<\theta \mathrm{S}$. The assumption that $\mathrm{c}_{\mathrm{L}}<\mathrm{c}_{\mathrm{H}}$ is natural. The assumption that $c_{\mathrm{H}}<\bar{\theta} \mathrm{S}$ ensures that both services are viable because it implies that at least at the top end of the market there are consumers who may wish to buy the high quality service (as well as the less costly low quality service) at marginal cost. Finally, we assume that the cost difference between the two services is not too large so that $\mathrm{c}_{\mathrm{H}}<\mathrm{c}_{\mathrm{L}} / \gamma$. As we shall see, this assumption plays a crucial role in the analysis. It implies that if the two services are priced at marginal costs, all consumers who wish to buy will prefer the high quality service over the low quality service. $^{2}$

In order to characterize the demands that the two retailers face, we illustrate in Figure 1 the utilities of consumers as a function of their types if they buy from retailers $\mathrm{L}$ and $\mathrm{H}$. In panel (a) we show the case where $p_{H} \leq \gamma p_{L}$. Then, all consumers who get a positive utility from buying are better-off buying from retailer $\mathrm{H}$. Hence, retailer L's market share is 0 in this case while retailer $\mathrm{H}$ serves all consumers with $\theta>\mathrm{p}_{\mathrm{H}} / \mathrm{S}$. In panel (b) we show the case where $\mathrm{p}_{\mathrm{H}}>$ $\gamma \mathrm{p}_{\mathrm{L}}$. Now consumers with $\theta \geq\left(\mathrm{p}_{\mathrm{H}}-\mathrm{p}_{\mathrm{L}}\right) /(1-\gamma) \mathrm{S}$ buy from retailer $\mathrm{H}$, consumers with $\theta \in\left(\mathrm{p}_{\mathrm{L}} / \gamma \mathrm{S}\right.$, $\left.\left(\mathrm{p}_{\mathrm{H}}-\mathrm{p}_{\mathrm{L}}\right) /(1-\gamma) \mathrm{S}\right)$ buy from retailer $\mathrm{L}$, and consumers with $\theta \leq \mathrm{p}_{\mathrm{L}} / \gamma \mathrm{S}$ do not buy at all. Noting that retailer $\mathrm{L}$ has a positive market share only if $\theta_{\mathrm{L}} \equiv \mathrm{p}_{\mathrm{L}} / \gamma \mathrm{S}>\theta_{\mathrm{H}} \equiv \operatorname{Max}\left\{\left(\mathrm{p}_{\mathrm{H}}-\mathrm{p}_{\mathrm{L}}\right) /(1-\gamma) \mathrm{S}, \mathrm{p}_{\mathrm{H}} / \mathrm{S}\right\}$, and recalling that the total mass of consumers is 1 and that $F(\theta)$ is the cumulative distribution of $\theta$, the demands that the two retailers are facing are given by

$$
Q_{H}=1-F\left(\theta_{H}\right), \quad Q_{L}=\operatorname{Max}\left\{F\left(\theta_{H}\right)-F\left(\theta_{L}\right), 0\right\}
$$

\section{The no vertical restraints benchmark}

We begin by establishing the no vertical restraints benchmark. As is well-known, if the manufacturer can only rely on a uniform wholesale price, we would have the familiar double marginalization problem (Sprengler, 1950). Since we wish to focus attention on the implications of vertical differentiation in retail for vertical restraints, we allow the manufacturer throughout

2 This assumption is analogous to Condition (F) in Shaked and Sutton (1983) which is necessary and sufficient for the "finiteness property" that says that a vertically differentiated industry with free entry can have a finite number of active firms. 
the paper to use two-part tariffs that consist of a wholesale price and a franchise fee. These tariffs eliminate the double marginalization problem and enable the manufacturer to fully capture the retailers' profits through the franchise fees.

Given a wholesale price $w$ and franchise fees $T_{H}$ and $T_{L}$, the profits of the two retailers are $\pi_{\mathrm{H}}(\mathrm{w})-\mathrm{T}_{\mathrm{H}}$ and $\pi_{\mathrm{L}}(\mathrm{w})-\mathrm{T}_{\mathrm{L}}$, where $\pi_{\mathrm{H}}(\mathrm{w}) \equiv\left(\mathrm{p}_{\mathrm{H}}-\mathrm{c}_{\mathrm{H}}-\mathrm{w}\right) \mathrm{Q}_{\mathrm{H}}$ and $\pi_{\mathrm{L}}(\mathrm{w}) \equiv\left(\mathrm{p}_{\mathrm{L}}-\mathrm{c}_{\mathrm{L}}-\mathrm{w}\right) \mathrm{Q}_{\mathrm{L}}$. It turns out that it is more convenient to express the profits of the two retailers in terms of $\theta_{\mathrm{H}}$ and $\theta_{\mathrm{L}}$, instead of $p_{H}$ and $p_{L}$. If $p_{H}>\gamma p_{L}$, then both retailers have positive market shares. Since in this case, $\theta_{H}$ $=\left(\mathrm{p}_{\mathrm{H}}-\mathrm{p}_{\mathrm{L}}\right) /(1-\gamma) \mathrm{S}$ and $\theta_{\mathrm{L}}=\mathrm{p}_{\mathrm{L}} / \gamma \mathrm{S}$, we can express the prices that the two retailers charge as $\mathrm{p}_{\mathrm{H}}=$ $\left(\theta_{\mathrm{L}}+(1-\gamma) \theta_{\mathrm{H}}\right) \mathrm{S}$ and $\mathrm{p}_{\mathrm{L}}=\theta_{\mathrm{L}} \gamma \mathrm{S}$. If $\mathrm{p}_{\mathrm{H}} \leq \gamma \mathrm{p}_{\mathrm{L}}$, only retailer $\mathrm{H}$ has a positive market share; since in this case, $\theta_{\mathrm{H}}=\mathrm{p}_{\mathrm{H}} / \mathrm{S}$, the price that retailer $\mathrm{H}$ charges can be expressed as $\mathrm{p}_{\mathrm{H}}=\theta_{\mathrm{H}} \mathrm{S}$. Therefore,

$$
\pi_{H}(w)=\left\{\begin{array}{cc}
\left(1-F\left(\theta_{H}\right)\right)\left(\left(\gamma \theta_{L}+(1-\gamma) \theta_{H}\right) S-c_{H}-w\right), & \theta_{H}>\theta_{L}, \\
\left(1-F\left(\theta_{H}\right)\right)\left(\theta_{H} S-c_{H}-w\right), & \theta_{H} \leq \theta_{L},
\end{array}\right.
$$

and

$$
\pi_{L}(w)=\left\{\begin{array}{cc}
\left(F\left(\theta_{H}\right)-F\left(\theta_{L}\right)\right)\left(\theta_{L} \gamma S-c_{L}-w\right), & \theta_{H}>\theta_{L} \\
0, & \theta_{H} \leq \theta_{L}
\end{array}\right.
$$

Given w, the two retailers simultaneously choose $\theta_{\mathrm{H}}$ and $\theta_{\mathrm{L}}$ to maximize their respective profits. We denote the Nash equilibrium choices by $\theta_{\mathrm{H}}(\mathrm{w})$ and $\theta_{\mathrm{L}}(\mathrm{w})$.

Since the manufacturer can use the franchise fees, $T_{L}$ and $T_{H}$, to fully extract the retailers' profits, he will set the wholesale price, $\mathrm{w}$, to maximize the following expression:

$$
\pi(w)=\pi_{H}(w)+\pi_{L}(w)+\left(Q_{H}(w)+Q_{L}(w)\right) w,
$$

where $\mathrm{Q}_{\mathrm{H}}(\mathrm{w})$ and $\mathrm{Q}_{\mathrm{L}}(\mathrm{w})$ are given by equation (2), evaluated at $\theta_{\mathrm{H}}(\mathrm{w})$ and $\theta_{\mathrm{L}}(\mathrm{w})$. The first two terms in equation (5) represent the manufacturer's income from franchise fees and the last term is the revenue from selling the product to the two retailers.

We now show that in equilibrium, retailer $\mathrm{L}$ is effectively foreclosed in the sense that the manufacturer will set $\mathrm{w}$ such that $\theta_{\mathrm{H}}(\mathrm{w})=\theta_{\mathrm{L}}(\mathrm{w})$ (equation (2) then shows that $\mathrm{Q}_{\mathrm{L}}=0$ ). To this 
end, note from the first lines of equations (3) and (4) that if $\theta_{H}(w)>\theta_{L}(w)$, the best-response functions of retailers $\mathrm{H}$ and $\mathrm{L}$ that determine $\theta_{\mathrm{H}}(\mathrm{w})$ and $\theta_{\mathrm{L}}(\mathrm{w})$ are defined respectively by

$$
\frac{\partial \pi_{H}(w)}{\partial \theta_{H}}=(1-\gamma) S\left(1-F\left(\theta_{H}\right)\right)-f\left(\theta_{H}\right)\left(\left(\gamma \theta_{L}+(1-\gamma) \theta_{H}\right) S-c_{H}-w\right)=0
$$

and

$$
\frac{\partial \pi_{L}(w)}{\partial \theta_{L}}=\gamma S\left(F\left(\theta_{H}\right)-F\left(\theta_{L}\right)\right)-f\left(\theta_{L}\right)\left(\gamma S \theta_{L}-c_{L}-w\right)=0,
$$

and intersect in the $\left(\theta_{\mathrm{H}}, \theta_{\mathrm{L}}\right)$ space below a 45 degrees line passing through the origin. From equation (6) it is easy to see that the best-response function of retailer $\mathrm{H}, \mathrm{BR}_{\mathrm{H}}$, is downward sloping in the $\left(\theta_{\mathrm{H}}, \theta_{\mathrm{L}}\right)$ space. Likewise, from equation (7) it is easy to see that the best response function of retailer $\mathrm{L}, \mathrm{BR}_{\mathrm{L}}$, is upward sloping in the $\left(\theta_{\mathrm{H}}, \theta_{\mathrm{L}}\right)$ space and crosses the 45 degrees line passing through the origin at $\theta_{\mathrm{L}}=\left(\mathrm{c}_{\mathrm{L}}+\mathrm{w}\right) / \gamma \mathrm{S}$ (when $\theta_{\mathrm{L}}=\left(\mathrm{c}_{\mathrm{L}}+\mathrm{w}\right) / \gamma \mathrm{S}$, equation (7) implies that $\left.\theta_{\mathrm{H}}=\theta_{\mathrm{L}}\right)$. Hence, $\mathrm{BR}_{\mathrm{L}}$ passes through the point $\left(\left(\mathrm{c}_{\mathrm{L}}+\mathrm{w}\right) / \gamma \mathrm{S},\left(\mathrm{c}_{\mathrm{L}}+\mathrm{w}\right) / \gamma \mathrm{S}\right)$. Returning to $\mathrm{BR}_{\mathrm{H}}$, if we substitute $\theta_{L}=\left(c_{L}+w\right) / \gamma S$ in equation (6), use the definition of $H(\theta)$, and rearrange terms, then equation (6) can be written as follows:

$$
H\left(\theta_{H}\right)=\theta_{H}-\frac{c_{H}-c_{L}}{(1-\gamma) S}
$$

Let $\theta^{*}$ be the solution to equation (8). Since $H(\theta)$ is nonincreasing, $\theta^{*}$ is defined uniquely. We therefore established that $\mathrm{BR}_{\mathrm{H}}$ passes through the point $\left(\theta^{*},\left(\mathrm{c}_{\mathrm{L}}+\mathrm{w}\right) / \gamma \mathrm{S}\right)$.

In Figure 2 we illustrate the best-response functions, $\mathrm{BR}_{\mathrm{H}}$ and $\mathrm{BR}_{\mathrm{L}}$, for two cases. In panel (a) we show the case where $\mathrm{w} \leq \mathrm{w}^{*} \equiv \gamma \mathrm{S} \theta^{*}-\mathrm{c}_{\mathrm{L}}$. Then $\mathrm{BR}_{\mathrm{H}}$ and $\mathrm{BR}_{\mathrm{L}}$ intersect below a 45 degrees line passing through the origin, implying that $\theta_{\mathrm{H}}(\mathrm{w})>\theta_{\mathrm{L}}(\mathrm{w})$, so by equation (2) both $\mathrm{Q}_{\mathrm{H}}$ and $\mathrm{Q}_{\mathrm{L}}$ are positive. In panel (b) we present the best-response functions when $\mathrm{w}>\mathrm{w}^{*} \equiv \gamma \mathrm{S} \theta^{*}-\mathrm{c}_{\mathrm{L}}$. Then $\mathrm{BR}_{\mathrm{H}}$ and $\mathrm{BR}_{\mathrm{L}}$ intersect above the 45 degrees line passing through the origin, in which case $\theta_{H}(w)<\theta_{L}(w)$, so retailer $L$ is effectively foreclosed.

When retailer $\mathrm{L}$ is foreclosed, retailer H's profit is given by the second line in equation (6). The first order condition for retailer H's problem is then given by 


$$
\frac{\partial \pi_{H}(w)}{\partial \theta_{H}}=S\left(1-F\left(\theta_{H}\right)\right)-f\left(\theta_{H}\right)\left(\theta_{H} S-c_{H}-w\right)=0 .
$$

Let $\theta_{\mathrm{H}}{ }^{0}(\mathrm{w})$ be the solution to equation (9). From equation (9) it is easy to see that $\theta_{\mathrm{H}}{ }^{0}(\mathrm{w})$ is increasing with $\mathrm{w}$. The reason for this is the familiar double marginalization problem: the higher is the wholesale price, the higher is the price charged by retailer $\mathrm{H}$, and hence, $\theta_{\mathrm{H}}$, which is the lowest type of consumer being served.

Next, we show that at the optimum, the manufacturer will set $w=w^{*}$. To this end, note that if $\mathrm{w}>\mathrm{w}^{*}$, the manufacturer's profit is

$$
\pi(w)=\left(1-F\left(\theta_{H}^{0}(w)\right)\right)\left(\theta_{H}^{0}(w) S-c_{H}-w\right)+\left(1-F\left(\theta_{H}^{0}(w)\right)\right) w .
$$

Recalling that $\theta_{\mathrm{H}}{ }^{0}(\mathrm{w})$ is increasing with $\mathrm{w}$ and using the envelope theorem, it follows that $\pi(\mathrm{w})$ is monotonically decreasing with $w$ because

$$
\frac{\partial \pi(w)}{\partial w}=-f\left(\theta_{H}^{0}(w)\right) w \frac{\partial \theta_{H}^{0}(w)}{\partial w}<0 .
$$

Hence the manufacturer will never set $\mathrm{w}>\mathrm{w}^{*}$. To show that $\mathrm{w}=\mathrm{w}^{*}$, note that whenever $\mathrm{w} \leq$ $\mathrm{w}^{*}$, the manufacturer's profit is given by

$$
\begin{aligned}
\pi(w)= & \left(1-F\left(\theta_{H}(w)\right)\right)\left(\left(\gamma \theta_{L}(w)+(1-\gamma) \theta_{H}(w)\right) S-c_{H}-w\right) \\
& +\left(F\left(\theta_{H}(w)\right)-F\left(\theta_{L}(w)\right)\right)\left(\theta_{L}(w) \gamma S-c_{L}-w\right)+\left(1-F\left(\theta_{L}(w)\right) w,\right.
\end{aligned}
$$

where the last expression is the manufacturer's income from selling the product to the two retailers (recall that the aggregate demand when both retailers are active is $\left(1-\mathrm{F}\left(\theta_{\mathrm{H}}\right)\right)+\left(\mathrm{F}\left(\theta_{\mathrm{H}}\right)-\right.$ $\left.\left.\mathrm{F}\left(\theta_{\mathrm{L}}\right)\right)=1-\mathrm{F}\left(\theta_{\mathrm{L}}\right)\right)$. Using the envelope theorem we obtain

$$
\begin{aligned}
\frac{\partial \pi(w)}{\partial w}= & {\left[\gamma S\left(1-F\left(\theta_{H}(w)\right)\right)-f\left(\theta_{L}(w)\right) w\right] \frac{\partial \theta_{L}(w)}{\partial w} } \\
& +f\left(\theta_{H}(w)\right)\left(\theta_{L}(w) \gamma S-c_{L}-w\right) \frac{\partial \theta_{H}(w)}{\partial w} .
\end{aligned}
$$

When $\mathrm{w}=\mathrm{w}^{*}$, equations (6) and (7) imply that $\theta_{\mathrm{H}}\left(\mathrm{w}^{*}\right)=\theta_{\mathrm{L}}\left(\mathrm{w}^{*}\right)=\theta^{*}$. This solution is unique 
since $\mathrm{BR}_{\mathrm{H}}$ is upward sloping and $\mathrm{BR}_{\mathrm{L}}$ is downward sloping so the two functions intersect at most once. Hence, evaluated at $\mathrm{w}^{*}$,

$$
\begin{aligned}
\frac{\partial \pi\left(w^{*}\right)}{\partial w} & =\left[\gamma S\left(1-F\left(\theta^{*}\right)\right)-f\left(\theta^{*}\right)\left(\theta^{*} \gamma S-c_{L}\right)\right] \frac{\partial \theta_{L}\left(w^{*}\right)}{\partial w} \\
& =\gamma S f\left(\theta^{*}\right)\left[H\left(\theta^{*}\right)-\theta^{*}+\frac{c_{L}}{\gamma S}\right] \frac{\partial \theta_{L}\left(w^{*}\right)}{\partial w} \\
& =\gamma f\left(\theta^{*}\right)\left(\frac{c_{L}-\gamma c_{H}}{1-\gamma}\right) \frac{\partial \theta_{L}\left(w^{*}\right)}{\partial w},
\end{aligned}
$$

where the last equality follows from equation (8). To determine the sign of this expression, note from equations (6) and (7) that both $\mathrm{BR}_{\mathrm{H}}$ and $\mathrm{BR}_{\mathrm{L}}$ shift upward in the $\left(\theta_{\mathrm{H}}, \theta_{\mathrm{L}}\right)$ space as $\mathrm{w}$ increases; since $\mathrm{BR}_{\mathrm{H}}$ is upward sloping and $\mathrm{BR}_{\mathrm{L}}$ is downward sloping, this implies that $\partial \theta_{\mathrm{L}}(\mathrm{w}) / \partial \mathrm{w}$ $>0$. Given the assumption that $c_{L} \geq \gamma c_{H}$, it therefore follows that $\partial \pi\left(w^{*}\right) / \partial w \geq 0$, implying that $\mathrm{w}<\mathrm{w}^{*}$ is never optimal. Since we already showed that $\mathrm{w}>\mathrm{w}^{*}$ is never optimal either, it follows that the best wholesale price from the manufacturer's point of view is $\mathrm{w}^{*}$. At the optimum, $\theta_{\mathrm{H}}\left(\mathrm{w}^{*}\right)=\theta_{\mathrm{L}}\left(\mathrm{w}^{*}\right)=\theta^{*}$, so retailer $\mathrm{L}$ is effectively foreclosed and retailer $\mathrm{H}$ charges a price $\mathrm{p}_{\mathrm{H}}=\mathrm{S} \theta^{*}$. Since $H(\theta)$ is a nonincreasing, it follows from equation (8) that $\theta^{*}$ increases with the gap between $c_{H}$ and $c_{L}$ and with $\gamma$, but decreases with $S$.

Proposition 1: Under optimal two-part tariffs, retailer $L$ is effectively foreclosed. The manufacturer sets the wholesale price equal to $w^{*}=\theta * \gamma S-c_{L}$ and retailer $H$ sets a retail price of $p_{H} *=\theta^{*}$ S and serves all consumers with $\theta>\theta *$, where $\theta *$ is increasing with the gap between $c_{H}$ and $c_{L}$ and with $\gamma$, and decreasing with $S$.

To interpret Proposition 1, note that since the manufacturer can extract the retailers' profits through the franchise fees, it would have been optimal for him to set a zero wholesale price to avoid a double marginalization problem. However, when the wholesale price is zero, the competition between the two retailers does not enable the manufacturer to maximize profits. Proposition 1 says that in order to maximize profits, the manufacturer raises the wholesale price 
to the point where retailer $\mathrm{L}$ cannot compete with retailer $\mathrm{H}$ and is hence effectively foreclosed. Although the foreclosure of retailer L means that the manufacturer does not reach low type consumers, the fact that high type consumers cannot switch to retailer $\mathrm{L}$ allows retailer $\mathrm{H}$ to charge a higher price and this benefits the manufacturer by allowing him to charge retailer $\mathrm{H} \mathrm{a}$ higher franchise fee. Interestingly, the foreclosure of retailer L holds for all values of $\gamma$ and is therefore independent of the degree to which the services of the two retailers are differentiated. Since $\mathrm{w}^{*}$ and $\mathrm{p}_{\mathrm{H}}{ }^{*}$ are increasing with $\theta^{*}$, Proposition 1 also implies that as the high quality service becomes more expensive relative to the low quality service (i.e, the gap between $\mathrm{c}_{\mathrm{H}}$ and $\mathrm{c}_{\mathrm{L}}$ increases) and as the two services become more similar (i.e., $\gamma$ increases), the manufacturer needs to set a higher wholesale price to foreclose retailer L. Since a higher wholesale price means that retailer $\mathrm{H}$ sets a higher retail price and serves fewer consumers, Proposition 1 suggests in turn that consumers are actually worse-off when there is a stronger competitive pressure by retailer L. That is, consumers are worse-off when the cost of low quality service (which is not offered in equilibrium) falls relative to the cost of the high quality service and when the quality of the low quality service increases and becomes more similar to the quality of the high quality service. Based on this result one might be tempted to guess that a refusal to deal with retailer $\mathrm{L}$ will benefit consumers by eliminating the competitive pressure that retailer L exerts. The next section however shows that this is not so.

We conclude this section by examining the robustness of the foreclosure result to the assumption that the manufacturer can fully extract the retailers' profits through the franchise fees. One might suspect that absent this assumption, the manufacturer may wish to deal with both retailers in order to expand the size market and boost his revenues from wholesale. We therefore consider now the extreme case where the manufacturer cannot use franchise fees and needs to rely only on the wholesale price. We show that even in this extreme case, the manufacturer forecloses retailer $\mathrm{L}$ in equilibrium. To facilitate the analysis, we only consider the case where the distribution of consumers' types is uniform on the interval $[0, \bar{\theta}]$. Then, equations (6) and (7) imply that the equilibrium in the downstream market is such that 


$$
\begin{gathered}
\theta_{H}(w)=\frac{2 c_{H}-c_{L}+2(1-\gamma) S \bar{\theta}+w}{(4-3 \gamma) S}, \\
\theta_{L}(w)=\frac{\gamma c_{H}+2(1-\gamma) c_{L}+\gamma(1-\gamma) S \bar{\theta}+(2-\gamma) w}{\gamma(4-3 \gamma) S},
\end{gathered}
$$

provided that

$$
w \leq w^{*} \equiv \frac{\gamma c_{H}-(2-\gamma) c_{L}+\gamma(1-\gamma) S \bar{\theta}}{2(1-\gamma)} .
$$

When $w \geq w^{*}, \theta_{H}(w)=\theta_{L}(w)$, so retailer $L$ is effectively foreclosed. We now wish to show that it is never optimal for the manufacturer to set $w<w^{*}$. To this end, note that if we substitute from equation (15) into equation (12), use the assumption that $F(\theta)$ is uniform, and rearrange terms, the manufacturer's profit becomes

$$
\pi(w)=\frac{\left(2(1-\gamma) c_{L}-\gamma c_{H}+\gamma(3-2 \gamma) S \bar{\theta}-(2-\gamma) w\right) w}{\gamma(4-3 \gamma) S \bar{\theta}}
$$

Differentiating this expression and evaluating the derivative at $\mathrm{w}=\mathrm{w}^{*}$ we obtain:

$$
\pi^{\prime}\left(w^{*}\right)=\frac{\left(2-\gamma^{2}\right) c_{L}-\gamma(3-2 \gamma) c_{H}+\gamma(1-\gamma)^{2} S \bar{\theta}}{\gamma\left(4-7 \gamma+3 \gamma^{2}\right) S \bar{\theta}} .
$$

Since $\pi(\mathrm{w})$ is concave, is sufficient to show that $\pi^{\prime}\left(\mathrm{w}^{*}\right)>0$. Noting that the denominator of $\pi^{\prime}\left(\mathrm{w}^{*}\right)$ is positive and recalling that by assumption, $\mathrm{c}_{\mathrm{L}}>\gamma \mathrm{c}_{\mathrm{H}}$, we have

$$
\begin{aligned}
\pi^{\prime}\left(w^{*}\right)> & \frac{\left(2-\gamma^{2}\right) \gamma c_{H}-\gamma(3-2 \gamma) c_{H}+\gamma(1-\gamma)^{2} S \bar{\theta}}{\gamma\left(4-7 \gamma+3 \gamma^{2}\right) S \bar{\theta}} \\
& =\frac{(1-\gamma)\left(S \bar{\theta}-c_{H}\right)}{\left(4-7 \gamma+3 \gamma^{2}\right) S \bar{\theta}}>0,
\end{aligned}
$$

where the last inequality follows because by assumption $S \bar{\theta}>c_{H}$ (i.e., the high quality service 
is viable). Hence, in equilibrium the manufacturer will set $\mathrm{w}$ above $\mathrm{w}^{*}$ and thereby effectively foreclose retailer $\mathrm{L}$.

The difference between this case and the case where the manufacturer can use franchise fees is that now, the optimal wholesale price will be set strictly above $\mathrm{w}^{*}$ which is lowest wholesale price needed to foreclose retailer L. To see that, note that when $F(\theta)$ is uniform, equation (9) implies that

$$
\theta_{H}^{0}(w)=\frac{c_{H}+S \bar{\theta}+w}{2 S} .
$$

Substituting this expression into equation (10), the manufacturer's profit when $\mathrm{w}>\mathrm{w}^{*}$ becomes

$$
\pi(w)=\frac{\left(-c_{H}+S \overline{\boldsymbol{\theta}}-w\right) w}{2 S \overline{\boldsymbol{\theta}}} .
$$

Differentiating this expression with respect to $\mathrm{w}$, evaluating the derivative at $\mathrm{w}=\mathrm{w}^{*}$, and using the assumption that $c_{L}>\gamma c_{H}$, we obtain:

$$
\begin{aligned}
\pi^{\prime}\left(w^{*}\right) & =\frac{\left(2-\gamma^{2}\right) c_{L}-c_{H}+(1-\gamma)^{2} S \bar{\theta}}{(1-\gamma) S \bar{\theta}}>\frac{\left(2-\gamma^{2}\right) c_{H}-c_{H}+(1-\gamma)^{2} S \bar{\theta}}{(1-\gamma) S \bar{\theta}} \\
& =\frac{(1-\gamma)\left(S \bar{\theta}-c_{H}\right)}{S \bar{\theta}}>0 .
\end{aligned}
$$

Proposition 2: Suppose that consumers' types are drawn from a uniform distribution on the interval $[0, \bar{\theta}]$. Then, if the manufacturer can only charge a uniform wholesale price per unit (but not franchise fees), the equilibrium wholesale price will be set strictly above $w^{*}$ which is the lowest wholesale price that ensures that the low quality retailer is foreclosed.

Once we established that it is optimal for the manufacturer to foreclose retailer L, it is not too surprising that the equilibrium wholesale price is strictly above $\mathrm{w}^{*}$. Intuitively, when the manufacturer deals only with retailer $\mathrm{H}$, there is a double marginalization problem. When it is 
possible to charge franchise fees, the manufacturer will set $\mathrm{w}$ as low as possible (subject to foreclosing retailer L) in order to alleviate the double marginalization problem as much as possible. But, if the manufacturer cannot use franchise fees, the manufacturer cannot avoid the double marginalization problem and hence $\mathrm{w}$ is set above $\mathrm{w}^{*}$.

\section{Vertical restraints when the market cannot be vertically segmented}

In this section we consider vertical restraints in markets that cannot be vertically segmented according to the consumers' willingness to pay for quality. The main result in this section is that the manufacturer will once again foreclose retailer L, although the use of vertical restraints benefits the manufacturer and hurts consumers.

We first consider the case where the manufacturer can assign one geographical territory with a total mass of $\lambda$ consumers to retailer $H$ and a second geographical territory with a mass of $1-\lambda$ consumers to retailer $L$. A priori, the benefit from exclusive territories is that they prevent the two retailers from competing directly with one another. To highlight the horizontal nature of the exclusive territories (vertical segmentation is considered in Section 5), suppose that the distribution of customers in the two territories is identical, except for the mass of consumers in each territory which is determined by the manufacturer. Again we assume that the manufacturer can use two-part tariffs.

Since each retailer is a monopolist is his territory, it is clearly optimal for the manufacturer to set $\mathrm{w}=0$ to avoid double marginalization. Consequently, retailers $\mathrm{H}$ and L, respectively, face the demand functions $\mathrm{Q}_{\mathrm{H}}=\lambda\left(1-\mathrm{F}\left(\theta_{\mathrm{H}}\right)\right)$ and $\mathrm{Q}_{\mathrm{L}}=(1-\lambda)\left(1-\mathrm{F}\left(\theta_{\mathrm{L}}\right)\right)$, where $\theta_{\mathrm{H}}=$ $\mathrm{p}_{\mathrm{H}} / \mathrm{S}$ and $\theta_{\mathrm{L}}=\mathrm{p}_{\mathrm{L}} / \gamma \mathrm{S}$ are the types of consumers who are just indifferent between buying and not buying. Again, it is more convenient to express the profits of the two retailers in terms of $\theta_{\mathrm{H}}$ and $\theta_{\mathrm{H}}$ rather than $\mathrm{p}_{\mathrm{H}}$ and $\mathrm{p}_{\mathrm{L}}$. Given $\theta_{\mathrm{H}}$ and $\theta_{\mathrm{L}}$, the two retailers charge the prices $\mathrm{p}_{\mathrm{H}}=\theta_{\mathrm{H}} \mathrm{S}$ and $\mathrm{p}_{\mathrm{L}}$ $=\theta_{L} \gamma S$, and their profits are $\pi_{H}(\lambda)-T_{H}$ and $\pi_{L}(\lambda)-T_{L}$, where $T_{L}$ and $T_{H}$ are the franchise fees and $\pi_{\mathrm{H}}(\lambda)=\lambda\left(1-\mathrm{F}\left(\theta_{\mathrm{H}}\right)\right)\left(\theta_{\mathrm{H}} \mathrm{S}-\mathrm{c}_{\mathrm{H}}\right)$ and $\pi_{\mathrm{L}}(\lambda)=(1-\lambda)\left(1-\mathrm{F}\left(\theta_{\mathrm{L}}\right)\right)\left(\theta_{\mathrm{L}} \gamma \mathrm{S}-\mathrm{c}_{\mathrm{L}}\right)$.

Since the manufacturer can extract the retailers' profits through the franchise fees, his profit is $\pi_{\mathrm{H}}(\lambda)+\pi_{\mathrm{L}}(\lambda)$. Since by assumption, $\gamma \mathrm{c}_{\mathrm{H}} \leq \mathrm{c}_{\mathrm{L}}$, it follows that $(1-\mathrm{F}(\theta))\left(\theta \mathrm{S}-\mathrm{c}_{\mathrm{H}}\right)>$ $(1-F(\theta))\left(\theta \gamma S-\gamma c_{H}\right) \geq(1-F(\theta))\left(\theta \gamma S-c_{L}\right)$ for all $\theta$, so the maximum profit that retailer $\mathrm{H}$ can make 
exceeds that of retailer L. Consequently, the manufacturer is better-off setting $\lambda=1$ and dealing exclusively with retailer $\mathrm{H}$. We shall therefore refer to this outcome as "exclusive dealings" or ED for short.

Given that the manufacturer deals exclusively with retailer $\mathrm{H}$, the profit of retailer $\mathrm{H}$, gross of the franchise fee, is $\pi_{\mathrm{H}}^{\mathrm{ED}}=\left(1-\mathrm{F}\left(\theta_{\mathrm{H}}\right)\right)\left(\theta_{\mathrm{H}} \mathrm{S}-\mathrm{c}_{\mathrm{H}}\right)$. The value of $\theta$ that maximizes this expression is determined by the following first order condition:

$$
\frac{\partial \pi_{H}^{E D}}{\partial \theta_{H}}=S\left(1-F\left(\theta_{H}\right)\right)-f\left(\theta_{H}\right)\left(\theta_{H} S-c_{H}\right)=0 .
$$

Recalling that $\mathrm{H}(\theta) \equiv(1-\mathrm{F}(\theta)) / \mathrm{f}(\theta)$, equation (23) can be rewritten as follows:

$$
H\left(\theta_{H}\right)=\theta_{H}-\frac{c_{H}}{S}
$$

Let $\theta^{* *}$ be the solution to equation (24). At the optimum, retailer $\mathrm{H}$ serves all consumers with $\theta>\theta^{*}$, and charges a price $\mathrm{p}_{\mathrm{H}}^{* *}=\theta^{* *} \mathrm{~S}$. Since $\mathrm{H}($.$) is nonincreasing, \theta^{* *}$ is defined uniquely. Moreover, $\theta^{* *}$ is increasing with $\mathrm{c}_{\mathrm{H}}$ and decreasing with $\mathrm{S}$; hence, retailer $\mathrm{H}$ charges a higher price when $c_{H}$ increases relative to $S$.

Next, suppose that the manufacturer cannot refuse to deal with retailer $\mathrm{L}$, but instead can engage in a Resale Price Maintenance (RPM). Note that since there are two levels of service, the manufacturer will set one price, $\mathrm{p}_{\mathrm{H}}$, for the high quality service and another price, $\mathrm{p}_{\mathrm{L}}$, for the low quality service. Since the manufacturer can fully extract the retailers' profits through the franchise fees, the resale prices $p_{H}$ and $p_{L}$ will be chosen to maximize the expression $\pi^{\mathrm{RPM}}=$ $\mathrm{Q}_{\mathrm{H}}\left(\mathrm{p}_{\mathrm{H}}-\mathrm{c}_{\mathrm{H}}\right)+\mathrm{Q}_{\mathrm{L}}\left(\mathrm{p}_{\mathrm{L}}-\mathrm{c}_{\mathrm{L}}\right)$, where $\mathrm{Q}_{\mathrm{H}}$ and $\mathrm{Q}_{\mathrm{L}}$ are given by equation (2). Again, it is more convenient to express the profits of the two retailers in terms of $\theta_{H}$ and $\theta_{L}$ instead of $p_{H}$ and $p_{L}$. As in Section 3 , if $\mathrm{p}_{\mathrm{H}}>\gamma \mathrm{p}_{\mathrm{L}}$, both retailers have positive market shares and the retail prices are $\mathrm{p}_{\mathrm{H}}=$ $\left(\theta_{\mathrm{L}}+(1-\gamma) \theta_{\mathrm{H}}\right) \mathrm{S}$ and $\mathrm{p}_{\mathrm{L}}=\theta_{\mathrm{L}} \gamma \mathrm{S}$. On the other hand, if $\mathrm{p}_{\mathrm{H}} \leq \gamma \mathrm{p}_{\mathrm{L}}$, only retailer $\mathrm{H}$ has a positive market share so the retail price is $p_{H}=\theta_{H} S$. Given these expressions, the manufacturer's profit can be written as follows: 


$$
\pi^{R P M}=\left\{\begin{array}{cc}
\left(1-F\left(\theta_{H}\right)\right)\left(\left(\gamma \theta_{L}+(1-\gamma) \theta_{H}\right) S-c_{H}\right) & \theta_{H}>\theta_{L}, \\
+\left(F\left(\theta_{H}\right)-F\left(\theta_{L}\right)\right)\left(\theta_{L} \gamma S-c_{L}\right), & \\
\left(1-F\left(\theta_{H}\right)\right)\left(\theta_{H} S-c_{H}\right), & \theta_{H} \leq \theta_{L}
\end{array}\right.
$$

Let $\theta_{\mathrm{H}}{ }^{\mathrm{RPM}}$ and $\theta_{\mathrm{L}}{ }^{\mathrm{RPM}}$ be the maximizers of $\pi^{\mathrm{RPM}}$. We now show that at the optimum, retailer $\mathrm{L}$ is once again foreclosed, i.e., $\theta_{\mathrm{H}}{ }^{\mathrm{RPM}} \leq \theta_{\mathrm{L}}{ }^{\mathrm{RPM}}$. To this end, assume by way of negation that $\theta_{\mathrm{H}}^{\mathrm{RPM}}>\theta_{\mathrm{L}}^{\mathrm{RPM}}$, so that both retailers have positive market shares. Then, the first order conditions for the manufacturer's problem are given by

$$
\frac{\partial \pi^{R P M}}{\partial \theta_{H}}=1-F\left(\theta_{H}\right)-f\left(\theta_{H}\right)\left(\theta_{H}-\frac{c_{H}-c_{L}}{(1-\gamma) S}\right)=0,
$$

and

$$
\frac{\partial \pi^{R P M}}{\partial \theta_{L}}=1-F\left(\theta_{L}\right)-f\left(\theta_{L}\right)\left(\theta_{L}-\frac{c_{L}}{\gamma S}\right)=0 .
$$

Using the definition of $H(\theta)$, equations (26) and (27) imply that $H\left(\theta_{H}{ }^{R P M}\right)=\theta_{H}{ }^{R P M}-c_{H} /(1-\gamma) S$ and $\mathrm{H}\left(\theta_{\mathrm{L}}{ }^{\mathrm{RPM}}\right)=\theta_{\mathrm{L}}{ }^{\mathrm{RPM}}-\mathrm{c}_{\mathrm{L}} / \gamma \mathrm{S}$. Since $\mathrm{H}($. $)$ is nonincreasing and since $\gamma \mathrm{c}_{\mathrm{H}} \leq \mathrm{c}_{\mathrm{L}}$, it follows that $\theta_{\mathrm{H}}{ }^{\mathrm{RPM}}<$ $\theta_{\mathrm{L}}^{\mathrm{RPM}}$, contradicting the assumption that $\theta_{\mathrm{H}}{ }^{\mathrm{RPM}}>\theta_{\mathrm{L}}{ }^{\mathrm{RPM}}$.

Given that $\theta_{\mathrm{H}}{ }^{\mathrm{RPM}}>\theta_{\mathrm{L}}{ }^{\mathrm{RPM}}$, the first order condition for $\theta_{\mathrm{H}}{ }^{\mathrm{RPM}}$ is

$$
\frac{\partial \pi^{R P M}}{\partial \theta_{H}}=S\left(1-F\left(\theta_{H}\right)\right)-f\left(\theta_{H}\right)\left(\theta_{H} S-c_{H}\right)=0 .
$$

Since this equation is identical to equation (23), it follows that $\theta_{H}{ }^{\mathrm{RPM}}=\theta^{* *}$. That is, the outcome under RPM is identical to the outcome under ED. To implement this outcome, the manufacturer will choose $\mathrm{p}_{\mathrm{H}}{ }^{\mathrm{RPM}}=\mathrm{p}_{\mathrm{H}}{ }^{* *} \equiv \theta^{* *} \mathrm{~S}$ and $\mathrm{p}_{\mathrm{L}}{ }^{\mathrm{RPM}} \geq \theta^{* *} \gamma \mathrm{S}$, which in turn ensure that $\theta_{\mathrm{L}}{ }^{\mathrm{RPM}}>\theta_{\mathrm{H}}{ }^{\mathrm{RPM}}=$ $\theta^{* *}$. Note that in fact, the manufacturer does not need to force manufacturer $\mathrm{H}$ to set $\mathrm{p}_{\mathrm{H}}{ }^{\mathrm{RPM}}=$ $\mathrm{p}_{\mathrm{H}}{ }^{* *}$, since a price floor of $\mathrm{p}_{\mathrm{H}}{ }^{* *}$ on the high quality service will be binding. Moreover, the manufacturer does not need to discriminate between the two retailers since the optimal outcome 
can be implemented by setting $\mathrm{p}_{\mathrm{H}}{ }^{* *}$ as a minimum RPM irrespective of the quality of service. Since $\gamma<1$, imposing the same price on both services ensures that only retailer $H$ can have a positive market share.

Proposition 3: Optimal RPM leads to the same outcome as exclusive dealings with retailer $H$ : at the optimum, retailer $H$ serves all consumers with $\theta>\theta^{* *}$ and charges a price $p_{H}^{* *}=\theta^{* * S}$, where $\theta^{* *}$ is increasing with $c_{H}$ and decreasing with $S$.

To examine the implications of vertical restraints we now compare the outcome under ED and RPM with the outcome under optimal two-part tariffs, using equations (8) and (16). Since $H(\theta)$ is a decreasing function, and since the assumption that $c_{L} \geq \gamma c_{H}$ implies that the right side of equation (8) exceeds the right side of equation (16), it follows that $\theta^{*} \leq \theta^{* *}$ and hence, $\mathrm{p}_{\mathrm{H}}{ }^{*}$ $\leq \mathrm{p}_{\mathrm{H}}{ }^{* *}$, with strict inequalities when $\mathrm{c}_{\mathrm{L}}>\gamma \mathrm{c}_{\mathrm{H}}$. That is, in the absence of vertical restraints, retailer $\mathrm{H}$ serves more consumers and charges a lower retail price. The reason for this is that when the manufacturer cannot use vertical restraints, he needs to lower the wholesale price in order to induce retailer $\mathrm{H}$ to set a sufficiently low wholesale price to ensure that consumers have no incentive to buy from retailer L. Moreover, as $\gamma$ gets closer to $c_{L} / c_{H}$, the right sides of equations (8) and (16) are becoming more similar to one another so the difference between $\theta^{*}$ and $\theta^{* *}$ and $\mathrm{p}_{\mathrm{H}} *$ and $\mathrm{p}_{\mathrm{H}}{ }^{* *}$ shrinks and approaches 0 as $\gamma$ approaches $\mathrm{c}_{\mathrm{L}} / \mathrm{c}_{\mathrm{H}}$.

Next we evaluate the impact of vertical restraints the manufacturer, on consumers, and on social welfare (defined as usual as the sum of consumers' surplus and firm's profits). ${ }^{3}$ First, note that under RPM the manufacturer can always choose the price that arises under optimal twopart tariffs, $\mathrm{p}_{\mathrm{H}}{ }^{*}$, instead of $\mathrm{p}_{\mathrm{H}}{ }^{* *}$; hence by revealed preferences it is obvious that the manufacturer is better-off when he can use RPM. Since the outcome under ED is identical to that under RPM, the same conclusion holds for ED.

As for consumers and social welfare, since $\mathrm{p}_{\mathrm{H}}^{*}=\theta^{*} \mathrm{~S}$ and $\mathrm{p}_{\mathrm{H}}{ }^{*}=\theta^{* *} \mathrm{~S}$, the aggregate consumer surplus and social welfare under optimal two-part tariffs, and under ED and RPM are

3 Since the manufacturer fully extracts the retailers' profits through the franchise fees, the retailers' payoffs are 0 irrespective of whether the manufacturer imposes vertical restraints or not. 
given by:

$$
C S(\theta)=\int_{\theta}^{\bar{\theta}}[\tilde{\theta} \gamma S-\theta \gamma S] d F(\tilde{\theta}), \quad \theta=\theta^{*}, \theta^{* *}
$$

and

$$
W(\theta)=C S(\theta)+\pi(\theta)=\int_{\theta}^{\bar{\theta}}\left[\theta S-c_{H}\right] d F(\theta), \quad \theta=\theta^{*}, \theta^{* *}
$$

Since $\theta^{*} \leq \theta^{* *}$, it is clear that $\operatorname{CS}\left(\theta^{*}\right) \geq \operatorname{CS}\left(\theta^{* *}\right)$ and $\mathrm{W}\left(\theta^{*}\right) \geq \mathrm{W}\left(\theta^{* *}\right)$, with strict inequalities when $c_{\mathrm{L}}<\gamma c_{\mathrm{H}}$. Hence, ED and RPM hurt consumers and lower social welfare. The intuition for this result is that under ED and RPM, retailer $\mathrm{H}$ serve fewer consumers than under two part tariffs so the associated deadweight loss is larger. Since the gap between $\theta^{*}$ and $\theta^{* *}$ shrinks as $\gamma$ gets closer to $\mathrm{c}_{\mathrm{L}} / \mathrm{c}_{\mathrm{H}}, \operatorname{CS}\left(\theta^{*}\right)$ and $\mathrm{W}\left(\theta^{*}\right)$ approach $\operatorname{CS}\left(\theta^{* *}\right)$ and $\mathrm{W}\left(\theta^{* *}\right)$ as $\gamma$ approaches $\mathrm{c}_{\mathrm{L}} / \mathrm{c}_{\mathrm{H}}$. This discussion can be summarized as follows:

Proposition 4: So long as $c_{L}<\gamma c_{H}$,ED and RPM benefit the manufacturer, hurt consumers, and lower social welfare. The gap between consumer surplus and social welfare shrinks as the services of the two retailers become more similar in the sense that $\gamma$ approaches $c_{L} / c_{H}$.

Proposition 4 implies that when retailers are vertically differentiated, ED and RPM are socially undesirable because they allow the manufacturer to foreclose retailer L without having to lower prices too much. One possible argument in favor of foreclosure is that it can eliminate the potential for a free-rider problem in the provision of services. In other words, if the quality of service is not completely fixed (as we have assumed), then dealing exclusively with retailer $\mathrm{H}$ may boost the retailer's incentive to incur the cost needed to enhance the quality of its service. Another possible argument in favor of foreclosure is that in the presence of asymmetric information regarding the quality of the manufacturer's product, the foreclosure of retailer L may signal the true quality to consumers. However, in Section 3 we already showed that vertical restraints are not needed to achieve foreclosure; hence, it is clear that the benefits associated with 
foreclosure can be achieved even without vertical restraints and therefore cannot be used in order to justify the use of vertical restraints.

\section{Customer restrictions}

This section considers markets that can be vertically segmented according to the willingness of different types of consumers to pay for quality. We show that in this kind of markets, the manufacturer will choose to impose Customer Restrictions (CR) on the retailers by requiring retailer $\mathrm{H}$ to deal only with high type consumers, while requiring retailer $\mathrm{L}$ to deal only with low type consumers. For instance, if large corporations have on average a higher willingness to pay than individuals, the manufacturer will require retailer $\mathrm{H}$ to deal exclusively with corporate customers and retailer L to deal exclusively with individuals. Likewise, ... Our main finding in this section is that the manufacturer will always use customer restrictions if he can and deal with both retailers. Relative to the case where retailer L is foreclosed, customer restrictions benefit not only the manufacturer but also low type consumers and possibly "intermediate" type consumers, although they harm high type consumers.

Under $\mathrm{CR}$ the manufacturer chooses a critical value of $\theta$, denoted by $\theta_{\mathrm{CR}}$ and assigns customers with $\theta \geq \theta_{\mathrm{CR}}$ to retailer $\mathrm{H}$ and customers with $\theta<\theta_{\mathrm{CR}}$ to retailer $\mathrm{L}$. The two retailers then become monopolists in their respective segments of the market and choose retail prices to maximize their profits. To avoid double marginalization, the manufacturer will set a 0 wholesale price and will extract the retailers' profits through franchise fees. As before, we simplify the analysis by expressing the profits of the two retailers in terms of $\theta_{\mathrm{H}}$ and $\theta_{\mathrm{L}}$ instead of $\mathrm{p}_{\mathrm{H}}$ and $\mathrm{p}_{\mathrm{L}}$. To this end, note that if $\theta_{\mathrm{H}} \geq \theta_{\mathrm{CR}}$, the choice of $\theta_{\mathrm{CR}}$ is not binding on retailer $\mathrm{H}$; since the utility of consumers who buy from retailer $H$ is $\theta S-p_{H}$, the price that retailer $H$ can charge is $p_{H}=\theta_{H} S$. If $\theta_{\mathrm{H}}<\theta_{\mathrm{CR}}$, the choice of $\theta_{\mathrm{CR}}$ is binding, so the price that retailer $\mathrm{H}$ can charge is $\mathrm{p}_{\mathrm{H}}=\theta_{\mathrm{CR}} \mathrm{S}$. Likewise, if $\theta_{\mathrm{L}} \leq \theta_{\mathrm{CR}}$, the utility of consumers who buy from retailer $\mathrm{L}$ is $\theta \gamma \mathrm{S}-\mathrm{p}_{\mathrm{L}}$, so the price that retailer $\mathrm{L}$ can charge is $\mathrm{p}_{\mathrm{L}}=\theta_{\mathrm{L}} \gamma \mathrm{S}$. If $\theta_{\mathrm{L}}>\theta_{\mathrm{CR}}$, all consumers prefer the high quality service so there is no demand for the low quality service.

Recalling that the wholesale price is 0 , the profits of the two retailers, gross of the franchise fees, are given by 


$$
\pi_{H}^{C R}\left(\theta_{H}\right)=\left\{\begin{array}{cc}
\left(1-F\left(\theta_{C R}\right)\right)\left(\theta_{C R} S-c_{H}\right), & \theta_{C R}>\theta_{H}, \\
\left(1-F\left(\theta_{H}\right)\right)\left(\theta_{H} S-c_{H}\right), & \theta_{C R} \leq \theta_{H},
\end{array}\right.
$$

and

$$
\pi_{L}^{C R}\left(\theta_{L}\right)=\left\{\begin{array}{cc}
\left(F\left(\theta_{C R}\right)-F\left(\theta_{L}\right)\right)\left(\theta_{L} \gamma S-c_{L}\right), & \theta_{C R}>\theta_{L}, \\
0, & \theta_{C R} \leq \theta_{L} .
\end{array}\right.
$$

Given $\theta_{\mathrm{CR}}$, let $\theta_{\mathrm{H}}{ }^{\mathrm{CR}}$ and $\theta_{\mathrm{L}}{ }^{\mathrm{CR}}$, respectively, be the maximizers of $\pi_{\mathrm{H}}\left(\theta_{\mathrm{H}}\right)$ and $\pi_{\mathrm{L}}\left(\theta_{\mathrm{L}}\right)$. Since the manufacturer can fully extract the retailers' profits through the franchise fees, he will choose $\theta_{\mathrm{CR}}$ to maximize the expression $\pi\left(\theta_{\mathrm{CR}}\right) \equiv \pi_{\mathrm{H}}{ }^{\mathrm{CR}}\left(\theta_{\mathrm{H}}{ }^{\mathrm{CR}}\right)+\pi_{\mathrm{L}}{ }^{\mathrm{CR}}\left(\theta_{\mathrm{L}}{ }^{\mathrm{CR}}\right)$. We denote the maximizer of $\pi\left(\theta_{\mathrm{CR}}\right)$ by $\theta_{\mathrm{CR}} *$.

From equation (32) it is easy to see that retailer $\mathrm{L}$ is foreclosed only if $\theta_{\mathrm{CR}} \leq \mathrm{c}_{\mathrm{L}} / \mathrm{S}{ }^{4}$ However, $\theta_{\mathrm{CR}} \leq \mathrm{c}_{\mathrm{L}} / \mathrm{S}$ cannot be optimal for the manufacturer since then, $\theta_{\mathrm{H}}{ }^{\mathrm{CR}}=\theta^{* *}$, which by equation (24) exceeds $c_{H} / S$, which in turn exceeds $c_{L} / S$. Therefore, consumers in the interval $\left[\theta_{\mathrm{CR}}, \theta^{* *}\right]$ are not served at all, implying that by raising $\theta_{\mathrm{CR}}$ above $\mathrm{c}_{\mathrm{L}} / \mathrm{S}$, retailer $\mathrm{L}$ can make a positive profit without affecting retailer H's profits. This establishes that it is never optimal to set $\theta_{\mathrm{CR}}$ so low that retailer $\mathrm{L}$ is foreclosed. It is worth noting that this conclusion holds even if the manufacturer cannot charge franchise fees: in fact in that case the conclusion is even stronger as the...

We now show that $\theta_{\mathrm{CR}} *$ is set sufficiently high so that $\theta_{\mathrm{H}}{ }^{\mathrm{CR}}=\theta_{\mathrm{CR}}{ }^{*}$; that is at the optimum, $\theta_{\mathrm{CR}}$ will be binding on retailer $\mathrm{H}$. To this end, note that if $\theta_{\mathrm{CR}} * \leq \theta_{\mathrm{H}}{ }^{\mathrm{CR}}$, then using the envelope theorem, it follows that

${ }^{4}$ If $\theta_{\mathrm{CR}}>\mathrm{c}_{\mathrm{L}} / \mathrm{S}$, then there exists a $\theta_{\mathrm{L}}{ }^{\mathrm{CR}} \in\left[\mathrm{c}_{\mathrm{L}} / \mathrm{S}, \theta_{\mathrm{CR}}\right]$ such that $\pi_{\mathrm{L}}{ }^{\mathrm{CR}}\left(\theta_{\mathrm{L}}{ }^{\mathrm{CR}}\right)>0$. Hence retailer $\mathrm{L}$ will operate in the market and will serve all consumer in the interval $\left[c_{L} / S, \theta_{L}{ }^{C R}\right]$. 


$$
\frac{d \pi\left(\theta_{C R}\right)}{d \theta_{C R}}=f\left(\theta_{C R}\right)\left(\theta_{L}^{C R} \gamma S-c_{L}\right)
$$

where, using equation (24), $\theta_{\mathrm{L}}^{\mathrm{CR}}$ is defined implicitly by the following first order condition:

$$
\frac{d \pi_{L}^{C R}\left(\theta_{L}\right)}{d \theta_{L}}=\gamma S\left(F\left(\theta_{C R}\right)-F\left(\theta_{L}\right)\right)-f\left(\theta_{L}\right)\left(\theta_{L} \gamma S-c_{L}\right)=0 .
$$

Equation (34) shows that $\theta_{\mathrm{L}}{ }^{\mathrm{CR}} \gamma \mathrm{S}>\mathrm{c}_{\mathrm{L}}$. Hence the right side of equation (34) is positive implying that the manufacturer will raise $\theta_{\mathrm{CR}}$ up to the point where it must exceed $\theta_{\mathrm{H}}{ }^{\mathrm{CR}}$. As a result, the first order condition for $\theta_{\mathrm{CR}} *$ is given by:

$$
\frac{d \pi\left(\theta_{C R}\right)}{d \theta_{C R}}=S\left(1-F\left(\theta_{C R}\right)\right)-f\left(\theta_{C R}\right)\left(\theta_{C R} S-\theta_{L}^{C R} \gamma S-\left(c_{H}-c_{L}\right)\right)=0,
$$

This condition can also be written as follows:

$$
H\left(\theta_{C R}\right)=\left(\theta_{C R}-\frac{c_{H}}{S}\right)-\left(\gamma \theta_{L}^{C R}-\frac{c_{L}}{S}\right) .
$$

It is important to note that in order to enforce CR, the manufacturer only needs to prevent retailer $\mathrm{L}$ from serving some customers that were assigned to retailer $\mathrm{H}$ but need not worry about the customers that buy from $\mathrm{H}$. To see why, note that given $\theta_{\mathrm{CR}}$ and $\theta_{\mathrm{L}}^{\mathrm{CR}}$, the equilibrium retail prices are $\mathrm{p}_{\mathrm{H}}{ }^{\mathrm{CR}}=\theta^{\mathrm{CR}} \mathrm{S}$ and $\mathrm{p}_{\mathrm{L}}{ }^{\mathrm{CR}}=\theta_{\mathrm{L}}{ }^{\mathrm{CR}} \gamma \mathrm{S}$, so the utility of a consumer who buys from retailer $\mathrm{H}$ is $U_{H}(\theta)=\theta S-\theta^{C R} S$, while the utility from buying from retailer $L$ is $U_{L}(\theta)=\theta \gamma S-\theta_{L}{ }^{C R} \gamma S$. Clearly, the difference between $\mathrm{U}_{\mathrm{H}}$ and $\mathrm{U}_{\mathrm{L}}$ is increasing with $\theta$ and $\mathrm{U}_{\mathrm{H}}\left(\theta^{\mathrm{CR}}\right)<\mathrm{U}_{\mathrm{L}}\left(\theta^{\mathrm{CR}}\right)$. Hence, consumers with $\theta \leq \theta^{\mathrm{CR}}$ never wish to buy from retailer $\mathrm{H}$, while some consumers with $\theta>\theta^{\mathrm{CR}}$ would be better-off switching to retailer $\mathrm{L}$. This means that the manufacturer needs to worry only about retailer L serving some of retailer's $H$ customers but never vice versa. Hence, it is sufficient to impose $C R$ only on retailer $L$ and prevent him from serving customers with $\theta \geq \theta^{\mathrm{CR}}$.

In order to compare $\mathrm{CR}$ with the vertical restraints examined in Section 4 , note that since $\gamma \mathrm{S} \theta_{\mathrm{L}}{ }^{\mathrm{CR}}>\mathrm{c}_{\mathrm{L}}$, the right side of equation (36) which defines $\theta_{\mathrm{CR}}{ }^{*}$ is smaller than the right side of equation (24) that defines $\theta^{* *}$, which is in turn smaller than the right side of equation (7) that 
defines $\theta^{*}$. Since the left side of all three equations is equal to $H(\theta)$ which is a decreasing function, it follows that $\theta_{\mathrm{CR}} *>\theta^{* *}>\theta^{*}$. Hence, retailer $\mathrm{H}$ will serve fewer consumers than he will under two-part tariffs or under ED and RPM.

Although retailer $\mathrm{H}$ serves fewer consumers than under optimal two-part tariffs, ED, and RPM, the fact that now retailer $\mathrm{L}$ is also active in the market means that it may well be the case that in total, CR enables more consumers to buy the manufacturer's product. To examine this issue, note that since retailer $\mathrm{H}$ serves consumers with $\theta \in\left[\theta^{\mathrm{CR}}, \bar{\theta}\right]$ while retailer $\mathrm{L}$ serves all consumers with $\theta \in\left[\theta_{\mathrm{L}}^{\mathrm{CR}}, \theta^{\mathrm{CR}}\right)$, the total sales of the manufacturer under $\mathrm{CR}$ are $1-\mathrm{F}\left(\theta_{\mathrm{L}}^{\mathrm{CR}}\right)$. On the other hand, the manufacturer's total sales under two-part tariffs are 1-F( $\left.\theta^{*}\right)$ and under ED or RPM they are given by $1-\mathrm{F}\left(\theta^{* *}\right)$. We now show that $\mathrm{CR}$ may either increase or decrease the total sales of the manufacturer, depending on $\gamma$ which measures the similarity between the services provided by the two retailers.

To establish the relationship between $\theta_{\mathrm{L}}{ }^{\mathrm{CR}}$ and $\theta^{*}$, let us evaluate the first order condition for $\theta_{\mathrm{L}}^{\mathrm{CR}}$ at $\theta^{*}$ :

$$
\begin{aligned}
\frac{d \pi_{L}^{C R}\left(\theta^{*}\right)}{d \theta_{L}} & =\gamma S\left(F\left(\theta_{C R}\right)-F\left(\theta^{*}\right)\right)-f\left(\theta^{*}\right)\left(\theta^{*} \gamma S-c_{L}\right) \\
& =-\gamma S\left(1-F\left(\theta_{C R}\right)\right)+\gamma S\left(H\left(\theta^{*}\right)-\theta^{*}\right) f\left(\theta^{*}\right)+f\left(\theta^{*}\right) c_{L} \\
& =-\gamma S\left(1-F\left(\theta_{C R}\right)\right)+f\left(\theta^{*}\right)\left(\frac{c_{L}-\gamma c_{H}}{1-\gamma}\right),
\end{aligned}
$$

where the third inequality follows by substituting for $\mathrm{H}\left(\theta^{*}\right)$ from equation (8) and rearranging terms. Evaluated at $\gamma=c_{L} / c_{H}$, the second term on the last line of equation (37) vanishes so the derivative is negative implying that $\theta_{\mathrm{L}}{ }^{\mathrm{CR}}<\theta^{*}$. By continuity then, $\theta_{\mathrm{L}}{ }^{\mathrm{CR}}<\theta^{*}$ for values of $\gamma$ that are sufficiently close to $\mathrm{c}_{\mathrm{L}} / \mathrm{c}_{\mathrm{H}}$.

Likewise, evaluating the first order condition for $\theta_{\mathrm{L}}^{\mathrm{CR}}$ at $\theta^{* *}$ and using equation (24), yields: 


$$
\frac{d \pi_{L}^{C R}\left(\theta^{* *}\right)}{d \theta_{L}}=-\gamma S\left(1-F\left(\theta_{C R}\right)\right)+f\left(\theta^{* *}\right)\left(c_{L}-\gamma c_{H}\right) .
$$

Evaluated at $\gamma=0$, the derivative is positive implying that $\theta_{\mathrm{L}}^{\mathrm{CR}}>\theta^{* *}$. By continuity then, $\theta_{\mathrm{L}}^{\mathrm{CR}}$ $>\theta^{* *}$ for values of $\gamma$ that are sufficiently close to 0 .

Proposition 5: Under CR, the manufacturer segments the market vertically by preventing retailer $L$ from serving consumers with $\theta \geq \theta_{C R}{ }^{*}$. As a result, retailer $H$ serves consumers with $\theta \in\left[\theta^{C R}, \bar{\theta}\right]$ and charges $p_{H}^{C R}=\theta_{C R}{ }^{*} S$, whereas retailer $L$ serves consumers with $\theta \in\left[\theta_{L}^{C R}, \theta^{C R}\right)$, and charges $p_{L}^{C R}=\theta_{L}^{C R} \gamma S$. When the retailers' services are relatively similar to one another in the sense that $\gamma$ is close to $c_{L} / c_{H}$, the low end of the market under CR is such that $\theta_{L}^{C R}<\theta^{*}<$ $\theta * *$. On the other hand, when the retailers' services are highly differentiated in the sense that $\gamma$ is close to 0 , the low end of the market under $C R$ is such that $\theta_{L}^{C R}>\theta^{* *}>\theta^{*}$.

Next we show that CR benefits the manufacturer. To this end, note that evaluated at $\theta^{\mathrm{CR}}$ $=\theta^{* *}$, the manufacturer's profit is

$$
\pi^{C R}\left(\theta^{* *}\right)=\left(1-F\left(\theta^{* *}\right)\right)\left(\theta^{* *} S-c_{H}\right)+\left(F\left(\theta^{* *}\right)-F\left(\theta_{L}^{C R}\right)\right)\left(\theta_{L}^{C R} \gamma S-c_{L}\right) .
$$

Since the first term on the right side is the manufacturer's profit under ED and under RPM, it follows from revealed preferences that the manufacturer is better-off under the optimal CR than under ED and RPM. Since earlier we showed that the manufacturer earns higher profits under ED and RPM than under optimal two-part tariffs, it follows that CR also dominates optimal twopart tariffs from the manufacturer's point of view. Intuitively, the manufacturer is better-off when he can impose CR because then the vertical segmentation of the market shields the high end of the market from competition from retailer $L$ (who cannot sell to consumers with $\theta \geq \theta_{\mathrm{CR}}$ ); hence it is now possible to raise prices at the high end of the market without having to foreclose retailer $\mathrm{L}$ and losing the ability to sell to low type consumers.

The impact of CR on consumers and on social welfare is more complex since we now need to distinguish among several possible cases. First, Proposition 5 shows that if $\gamma$ is close to 
0 , then $\theta_{\mathrm{L}}^{\mathrm{CR}}>\theta^{* *}>\theta^{*}$. These inequalities imply that under CR fewer consumers are served, and moreover, some consumers that were previously served by retailer $\mathrm{H}$ are now served by retailer $\mathrm{L}$ and therefore get a lower quality of service. As a result, in this case CR unambiguously hurts consumers and lowers social welfare.

Second, when $\gamma$ is close to $c_{L} / c_{H}$, Proposition 5 shows that $\theta_{L}{ }^{C R}<\theta^{*}<\theta^{* *}$. To save space, we only compare consumer surplus and social welfare under CR and under ED and RPM; the comparison of CR with optimal two-part tariffs is then completely analogous. Since $\theta_{\mathrm{L}}^{\mathrm{CR}}<$ $\theta^{* *}$, we need to distinguish among three groups of consumers. The first group has consumers with $\theta \in\left[\theta_{\mathrm{L}}^{\mathrm{CR}}, \theta^{* *}\right)$, who are served by retailer $\mathrm{L}$ under $\mathrm{CR}$ but are not served at all under ED and RPM where retailer L is foreclosed. Hence by revealed preference (i.e., the fact that they buy under CR), it is clear that CR benefits consumers in the first group. The second group contains consumers with $\theta \in\left[\theta^{* *}, \theta^{\mathrm{CR}}\right)$. Under ED and RPM, these consumers are served by retailer $\mathrm{H}$ and pay $\mathrm{p}_{\mathrm{H}}^{* *}=\theta^{* *} \mathrm{~S}$, so their utility is $\mathrm{U}^{* *}(\theta)=\theta \mathrm{S}-\theta^{* *} \mathrm{~S}$; under CR they are served by retailer $L$ and pay $p_{L}{ }^{C R}=\theta_{L}{ }^{C R} \gamma S$, so their utility is $U^{C R}(\theta)=\theta \gamma S-\theta_{L}{ }^{C R} \gamma S$. To examine the implication of this difference, let $\Delta(\theta) \equiv \mathrm{U}^{\mathrm{CR}}(\theta)-\mathrm{U}^{* *}(\theta)$ and note that $\Delta^{\prime}(\theta)=$ $-(1-\theta)<0$; hence, low types within the second group are more likely to benefit from CR. It is now easy to check that $\Delta\left(\theta^{* *}\right)=\left(\theta^{* *} \theta_{-} \theta_{\mathrm{L}}^{\mathrm{CR}}\right) \gamma \mathrm{S}>0$, so CR surely enhances consumer surplus at the bottom end of the second group. At the top end of the second group, $\Delta\left(\theta^{\mathrm{CR}}\right)=\left(\theta^{* *}-\gamma \theta_{\mathrm{L}}^{\mathrm{CR}}-(1-\right.$ $\left.\gamma) \theta^{\mathrm{CR}}\right) \mathrm{S}$. But since $\gamma$ is close to $\mathrm{c}_{\mathrm{L}} / \mathrm{c}_{\mathrm{H}}$, Proposition 5 implies that $\theta_{\mathrm{L}}^{\mathrm{CR}}<\theta^{*}<\theta^{* *} \ldots$

Finally, the third group of consumers are those with $\theta \in\left[\theta^{\mathrm{CR}}, \bar{\theta}\right]$. These consumers are served by retailer $\mathrm{H}$ under both CR, ED, and RPM, so their utility is only affected by the prices they pay. Since $\mathrm{p}_{\mathrm{H}}{ }^{*}<\mathrm{p}_{\mathrm{H}}^{\mathrm{CR}}, \mathrm{CR}$ surely hurts consumers in the third group.

We now summarize this discussion in the following proposition.

Proposition 6: The manufacturer always prefers $C R$ to a vertical foreclosure of retailer $L$. As for consumers, then there exist $\theta^{*} \in\left[\theta_{L}^{C R}, \theta_{H}^{V F}\right)$ such that consumers whose $\theta$ is less than $\theta^{*}$ are better-off whereas consumers whose $\theta$ is above $\theta^{*}$ are worse-off under CR than they are under vertical foreclosure.

To be continued!!! 


\section{References}

Bolton P. and G. Bonano (1988), "Vertical Restraints in A Model of Vertical Differentiation," Vol. 103, 555-570.

Comanor W. and Frech K. (1985), "The competitive Effects of Vertical Agreements," American Economic Review, Vol. 57,

Comanor W. and P. Rey (1997), "Competition Policy towards Vertical Restraints in Europe and the United States," Empirica, Vol. 24, 37-52.

Easterbrook F. (1984), "Vertical arrangement and The Rule of Reason," Antitrust Law Journal, Vol. 53, ....

Katz M. (1989), "Vertical Contractual Relations," Ch. 11 in Schmalensee R. and Willig R. (eds.), Handbook of Industrial Organization, North Holland.

Marvel H. and S. McCafferty (1984), "Resale Price Maintenance and Quality Certification," Rand Journal of Economics, Vol. 15, 340-359.

Matheweson F. and R. Winter (1985), Competition Policy and Vertical Exchange, Toronto: University of Toronto Press.

Matheweson F. and R. Winter (1985), "The Law and Economics of Resale Price Maintenance," Review of Industrial Organization, Vol. 13, 57-84.

Rey P. and J. Tirole (1986), "The Logic of Vertical Restraints," American Economic Review, Vol. 76, 921-939.

Shaked A. and J. Sutton (1983), "Natural Oligopoly," Econometrica, Vol. 51, 1469-1484.

Sprengler J. (1950), "Vertical Integration and Antitrust Policy," Journal of Political Economy, Vol. 58, 347-352.

Telser L. (1960), "Why Should Manufacturers want Free Trade," Journal of Law and Economics, Vol 3, 86-105.

Tirole J. (1988), The Theory of Industrial Organization, Cambridge, MA: The MIT Press.

Winter R. (1993), "Vertical Control and Price Versus Nonprice Competition," Quarterly Journal of Economics, Vol. 108, 61-75. 